\title{
Peginterferon Pharmacokinetics in African American and Caucasian American Patients with Hepatitis C Virus Genotype 1 Infection
}

\author{
Charles D. Howell ${ }^{1}$, Thomas C. Dowling ${ }^{2}$, Marika Paul ${ }^{3}$, Abdus S. Wahed ${ }^{3}$, Norah A. \\ Terrault $^{4}$, Milton Taylor ${ }^{5}$, Lennox Jeffers ${ }^{6}$, and Jay H. Hoofnagle ${ }^{7}$ for the Virahep-C Study \\ Group \\ ${ }^{1}$ University of Maryland Baltimore School of Medicine \\ ${ }^{2}$ University of Maryland Baltimore School of Pharmacy \\ ${ }^{3}$ University of Pittsburgh \\ ${ }^{4}$ University of California San Francisco \\ ${ }^{5}$ Indiana University, Bloomington \\ ${ }^{6}$ University of Miami School of Medicine \\ ${ }^{7}$ National Institutes of Health, Bethesda
}

\section{Abstract}

Background \& Aims-The relationship between serum peginterferon pharmacokinetics and pharmacodynamics and the early virologic response (EVR) to peginterferon and ribavirin therapy was assessed in patients with chronic hepatitis $\mathrm{C}$ virus (HCV) genotype 1 infection in the VirahepC study.

Methods-333 patients [160 African Americans (AA) and 173 Caucasian Americans (CA)] who received peginterferon alfa-2a $(180 \mu \mathrm{g} / \mathrm{wk})$ without a dose modification during the initial 4 weeks of therapy were analyzed. Peginterferon and 2,5-OAS serum levels were measured on days $0,1,2$, 3, 7, 14, 28, 56, 84, and 168 of treatment. The EVR: $\left(\geq 2 \log _{10}\right.$ decline in HCV RNA levels by week 12 of therapy) was the primary virologic endpoint.

Results-Peginterferon pharmacokinetics after the first dose were similar in AA and CA, but AA had greater peginterferon concentrations at days $1,3,14$ and $28(\mathrm{p}<0.05)$. AA had higher absolute serum 2,5-OAS levels on days $0,1,2,3,7,14,28$ and 56 ( $\mathrm{p}<0.05$ ), but the magnitude of 2,5-OAS induction during treatment relative to day 0 were similar. AA patients exhibited a smaller decline in serum HCV RNA during the first 28 days of treatment ( $p<0.001$ ) and a lower EVR (65\% vs. 83\%). AA and CA with EVR had significantly higher serum peginterferon concentrations and serum 2,5OAS induction during the first 12 weeks than patients without an EVR.

Correspondence:Charles D. Howell, M.D., 22 South Greene St. N3W50, Baltimore, MD 21201, Phone: 410-328-1358, Fax: 410-328-1897, Email: E-mail: chowell@umaryland.edu.

Publisher's Disclaimer: This is a PDF file of an unedited manuscript that has been accepted for publication. As a service to our customers we are providing this early version of the manuscript. The manuscript will undergo copyediting, typesetting, and review of the resulting proof before it is published in its final citable form. Please note that during the production process errors may be discovered which could affect the content, and all legal disclaimers that apply to the journal pertain. 
Conclusion-Peginterferon alfa-2a pharmacokinetic and pharmacodynamic variability is associated with EVR in both AA and CA with $\mathrm{HCV}$ infection, but do not explain the racial disparity in combination treatment efficacy.

The efficacy of peginterferon alfa and ribavirin treatment for chronic hepatitis $\mathrm{C}$ virus (HCV) infection varies by several viral and host factors including HCV genotype, pretreatment $\mathrm{HCV}$ RNA serum concentrations, amount of liver fibrosis, patient sex, age and race. African Americans have the highest prevalence of anti-HCV (3.0\%) in the United States, followed by Mexican Americans (1.3\%) and Non-Hispanic White Americans (1.5\%) ${ }^{1}$. Strikingly, African Americans also have the lowest rates of sustained clearance of $\mathrm{HCV}$ following treatment with alpha interferon (standard or pegylated) with and without ribavirin ${ }^{2-4}$. The basis for this racial difference in efficacy of antiviral therapy is unknown.

The study of Viral Resistance to Antiviral Therapy for Chronic Hepatitis C (Virahep-C) was a prospective, multi-center study designed to assess the rates of response to peginterferon alfa-2a plus ribavirin therapy in African American (AA) and Caucasian American (CA) patients with chronic hepatitis $\mathrm{C}$ and $\mathrm{HCV}$ genotype 1 infection and to attempt to elucidate the reasons for racial differences in response rates 4 . The sustained virological response (SVR) rate - defined as lack of detectable serum HCV RNA 24 weeks after treatment - was significantly lower among AA than CA patients ( 28 vs. $52 \%$ : p <0.001). The lower virological response among AA was apparent during the first month of treatment as shown by differences in rates of decrease in HCV RNA concentrations. Several clinical features that differed between the AA and CA patient cohorts, such as body mass index, insulin resistance, and total amount of peginterferon and ribavirin taken, were associated with a lower SVR rate in the total study population. However, these factors did not account for the racial disparity in the SVR rate in multivariable regression analysis 4 .

Alpha interferons mediate antiviral effects by binding to the type I interferon receptor located in the plasma membranes of diverse cell types ${ }^{5}$. Cross-linking of type I interferon receptors activates Jak-1 and Tyk kinases that phosphorylate signaling transducers of activation and transcription (STAT) 1 and 2 proteins. Phosphorylation induces STAT-1 and STAT-2 dimerization, translocation to the nucleus, and transcriptional activation of hundreds of interferon-stimulated genes ${ }^{6}$. Hypothetically, defects in either peginterferon pharmacokinetics (i.e. absorption, distribution, metabolism and elimination) or pharmacodynamics (i.e. binding to the type I IFN receptor and downstream signal transduction) could result in lower HCV clearance rates. Previous studies have found considerable inter-individual variability in peginterferon pharmacokinetics among patients with chronic hepatitis $\mathrm{C}$, though the relationship between pharmacokinetic variability to treatment efficacy is controversial ${ }^{7-9}$. Ethnicity and race are important demographic factors that contribute to the variability in pharmacokinetics and pharmacodynamics for many drugs. For example, propranolol clearance is up to 76\% higher in AA relative to CA, possibly due to increased CYP1A2 or CYP2D6mediated drug metabolism 10,11 . Also, significant ethnic differences exist in the polymorphic hepatic NAD(P)H:quinone oxidoreductase activity that is important for hepatic metabolism of quinones and activation of anti-cancer drugs such as mitomycin $\mathrm{C}^{12}$. Moreover, lower plasma efavirenz clearance has been associated with a cytochrome P450 2B6 gene (CYP2B6) polymorphism (516G-->T) that is more frequent among African Americans compared to Americans of European descent ${ }^{13}$. The objective of the present study was to determine the relationship between serum peginterferon pharmacokinetics and pharmacodynamics and early virologic response (EVR) ( $\geq 2-\log _{10}$ decline or undetected serum HCV RNA at week 12) during combination treatment in patients infected with $\mathrm{HCV}$ genotype 1 overall and within AA and CA racial groups in the Virahep-C study. 


\section{Materials and Methods}

\section{Study Population}

A total of 401 patients (196 AA and $205 \mathrm{CA}$ ) between 18 and 70 years of age with chronic $\mathrm{HCV}$ genotype 1 infections and no previous HCV antiviral treatment were enrolled in the Virahep C study ${ }^{4}$. All patients had a serum HCV RNA concentration $\geq 600 \mathrm{IU} / \mathrm{ml}$ and 399 had a liver biopsy prior to treatment that showed evidence of chronic hepatitis C. Subjects were treated with peginterferon alfa-2a (Pegasys ${ }^{\mathrm{TM}}$; Roche Pharmaceuticals, Nutley, NJ) $180 \mu \mathrm{g}$ s.c. weekly and ribavirin (Copegus: Roche Pharmaceuticals) $1000 \mathrm{mg}$ or $1200 \mathrm{mg}$ per day (based on body weight of $<75 \mathrm{~kg}$ or $\geq 75 \mathrm{~kg}$ ) for up to 48 weeks. Patients who had detectable HCV RNA in the serum at week 24 of treatment were considered non-responders, and therapy was discontinued. Patients without detectable HCV RNA in serum at week 24 were continued on treatment for a total of 48 weeks. All patients were followed for at least six months after stopping therapy. The amount of peginterferon and ribavirin taken was monitored using electronic Medication Event Management System (MEMS: Aardex, Zug, Switzerland) caps that were placed on both the peginterferon and ribavirin containers ${ }^{4}$. MEMS caps recorded the date and time the containers were opened, an indication of medication use. The primary Virahep-C study endpoint was a sustained virological response (SVR), defined as a lack of detectable serum HCV RNA 24 weeks after therapy was discontinued. All patients provided written informed consent. The protocol and consent form were approved by local Institutional Review Boards as well as a designated Data Safety and Monitoring Board.

\section{Pharmacokinetics and Pharmacodynamics Study Design}

Three hundred thirty three patients (160 AA and $173 \mathrm{CA}$ ) who were $100 \%$ adherent to peginterferon alfa-2a $180 \mu \mathrm{g}$ per week during the first 4 weeks of treatment as assessed by MEMS were included in this pharmacokinetic analysis. More than $90 \%$ of AA and CA who met this inclusion criterion received $\geq 90 \%$ of the intended dose of peginterferon during the first 12 weeks treatment. The number of subjects enrolled at separate Virahep-C clinical centers ranged from 31 to 56 (median 41). Pharmacokinetics were assessed based upon serum peginterferon concentrations measured by enzyme-linked immunoassay (Roche Molecular Diagnostics; Alameda, CA) with a lower limit of sensitivity of $251 \mathrm{pg} / \mathrm{ml}$ and a dynamic range of $350-3000 \mathrm{pg} / \mathrm{ml}{ }^{9}$. Peginterferon pharmacodynamic activity was assessed based upon changes in serum 2,5-OAS activity, an enzyme induced by interferon alpha. Serum 2,5-OAS activity was determined using a commercially available radioimmunoassay kit (Roche Molecular Diagnostics) ${ }^{9}$. Peginterferon alfa-2a pharmacokinetic data were analyzed by noncompartmental methods (WinNonlin; Pharsight Corp., Mountain View, CA). Initially, serum for peginterferon and 2,5-oligoadenylate synthetase (OAS) concentrations were drawn on day 0 immediately before the first injection of peginterferon and on treatment days 1, 2, 3, 7, 14, 28 , and every 4 weeks thereafter. Phlebotomy on day 3 was discontinued after 135 patients had been enrolled in the Virahep-C study. Thus, the maximum serum concentration (Cmax), minimum (trough) serum concentration (Cmin), time to maximum concentration (Tmax) and area under the serum concentration-time curve (AUC) from day 0 to 7 following the first peginterferon dose were determined for 91 of the 135 patients who had peginterferon serum concentrations obtained on days $0,1,2,3$, and 7 and who also met the peginterferon adherence inclusion criteria. Minimum or trough serum peginterferon concentrations (Cmin) were obtained at days $14,28,56$, and 84 before peginterferon injection in all 333 patients. The peginterferon accumulation ratio was calculated as the ratio of the week-24: week-1 Cmin values. Renal function was estimated by the Cockcroft-Gault equation for creatinine clearance (CLcr). 


\section{Virological Studies}

All HCV tests were performed at a central laboratory (SeraCare BioServices, Gaithersburg, MD) ${ }^{4}$. Serum HCV RNA concentrations were tested using the COBAS Amplicor Hepatitis C Virus Monitor Test, version $2.0^{\mathrm{TM}}$ assay (sensitivity $600 \mathrm{IU} / \mathrm{ml}$ : Roche Molecular Diagnostics, Alameda, CA). Samples testing negative using this quantitative assay were tested in duplicate using the Amplicor ${ }^{\mathrm{TM}}$ assay (sensitivity $50 \mathrm{IU} / \mathrm{ml}$; Roche Molecular Diagnostics). HCV genotyping was performed with the VERSANT ${ }^{\mathrm{TM}} \mathrm{HCV}$ Genotype (line probe hybridization) Assay (Bayer, Tarrytown, NY). The EVR defined as a $\geq 2-\log _{10}$ decrease in serum HCV RNA concentration relative to baseline or an undetected serum HCV RNA at week 12 was the primary virological endpoint for the present study.

\section{Statistical Analysis}

Baseline demographic, clinical and virological characteristics of the racial groups were compared using the Pearson chi-square test for association with continuity correction or exact tests for differences in proportions. The non-parametric Wilcoxon rank-sum test was used to assess whether distributions of continuous data differed significantly between the two racial groups. To identify the host factors associated with Cmax and AUC, linear regression analysis was used with the square-root transformed Cmax and AUC as dependent variables. The association between Tmax and baseline characteristics was explored using logistic regression models for dichotomous Tmax ( $\leq 3$ days vs. $>3$ days) as outcome. Linear mixed models were employed to investigate the association between longitudinal log viral levels over the first 28 days and the pharmacokinetic parameters in the 91 patients with first-dose peginterferon PK data. Such models take into account the correlations between observations within the same patients over time. Since the log viral levels were not linear in time, a square root transformation of time in weeks was performed to approximate viral levels with a linear model. The covariates included in the model are race, Cmax, Cmin, Tmax, AUC and their interactions with time.

The relationships between 28-day peginterferon level (dependent variable) and demographic and clinical covariates such as race, age, viral level and renal function were evaluated using linear regression analysis. Spearman rank correlations were used to explore the relationships between peginterferon levels, 2,5-OAS levels and HCV RNA levels at different time points. A correlation coefficient $(r) \geq 0.30$ with $p$-value $<0.05$ was deemed to be significant. For all other analysis, $\mathrm{p}<0.05$ was used to determine the statistical significance. A linear mixed model of HCV RNA levels as outcome and peginterferon and 2,5-OAS levels along with race as covariates was employed to assess the relationships of viral levels with peginterferon levels and 2,5-OAS levels. A separate linear mixed model for peginterferon concentrations was fit to assess its relationship with race and the 2,5-OAS levels over time (days treated as categories). For this model, robust standard errors were used for tests of significance. Association of EVR with race, peginterferon levels and 2,5-OAS levels were investigated by using log-linear regression and results are reported as estimates of relative risks and confidence intervals.

\section{Results}

\section{Patient Characteristics}

Table 1 shows the baseline characteristics of 333 patients who received full doses of peginterferon during the first 28 days of therapy. Compared to CA patients, AA patients had a higher BMI and were more likely to have a history of diabetes and of hypertension. In addition, AA patients also had a significantly lower serum ALT, albumin and total bilirubin level than CA ( $\mathrm{p}<0.05)$. Also, AA patients were more likely to have HCV genotype $1 \mathrm{~b}$ than CA patients $(p=0.005)$. There were no statistically significant differences in the baseline serum HCV RNA levels, patient age, estimated duration of HCV infection, history of alcohol and tobacco use, hepatic steatosis, liver necroinflammatory score and liver fibrosis score between 
the two racial groups. Similar racial differences in clinical features were also found in the entire cohort of 401 patients enrolled in the Virahep-C study ${ }^{4}$. Sixty eight patients with $<100 \%$ adherence to full-dose peginterferon during the first 28 days were excluded. Compared to patients included in the PK study, excluded patients were more likely to be female ( $48.5 \%$ vs. $32.1 \%, \mathrm{p}=0.01)$ and to have lower EVR (50\% vs. $74.3 \%$; $<$ < 0.0001$)$, end of treatment virologic responses (undetected serum HCV RNA at week 48$)(38.1 \%$ vs. $58.9 \% ; \mathrm{p}=0.015)$ and SVR $(32.1 \%$ vs. $41.7, \mathrm{p}=0.15) \%$. There were no significant differences between included and excluded patients in racial classification, baseline age, body weight, body mass index, serum ALT, blood hemoglobin, HCV viral load, hepatic steatosis, Ishak fibrosis score, and prevalence of bridging fibrosis and cirrhosis.

\section{Peginterferon serum concentrations and pharmacokinetics}

Median serum peginterferon concentrations and interquartile ranges (IQR) from baseline (day 0 ) through treatment day 84 (wk. 12) are shown in Figure 1 (day $0-7$ shown in insert). Peginterferon was detectable on day 1 and peak concentrations were achieved by day 2-3 after the first injection, followed by a trough level on day 7 (week 1). Peginterferon trough concentrations increased gradually after subsequent doses and reached a steady state at week 8. Peginterferon concentrations were significantly higher among AA than CA patients on days $1(\mathrm{p}=0.02), 2(\mathrm{p}=0.03), 14(\mathrm{p}=0.03)$, and $28(\mathrm{p}=0.006)$. Thereafter, peginterferon concentrations did not differ significantly between the two racial groups [p>0.68 for weeks 8 , 12, and 24 (data not shown)].

Peginterferon pharmacokinetic variables after the first dose were analyzed in $40 \mathrm{AA}$ and 51 CA patients who had a day 3 serum specimen and who also received peginterferon without a dose modification or missed dose for the first 28 days of treatment. Results by racial group are shown in Table 2. Tmax values were less likely to be $\leq 3$ days in CA than in AA patients [74\% vs. $93 \%, \mathrm{OR}=0.24$ (CA vs. AA), $\mathrm{p}=0.045$ ], but $\mathrm{Cmax}, \mathrm{Cmin}$ and AUC after the first dose did not differ significantly between the two racial groups. In addition, there was no racial difference in the median peginterferon accumulation ratio, either among the 91 patients with first dose pharmacokinetic parameters (Table 1) or the total cohort (AA: 2.67, IQR $(1.78,3.71)$; CA 2.62, $\operatorname{IQR}(1.94,4.32) ; p=0.28)]$. In logistic regression analyses with an indicator variable for Tmax $(1: \leq 3$ days, $0:>3$ days) as the dependent variable, patient gender $(\mathrm{p}=0.71)$, body weight ( $\mathrm{p}$ $=0.50)$, BMI $(p=0.98)$ and serum creatinine $(p=0.41)$ were not significantly associated with Tmax. When adjusted for these baseline covariates, the association of race with Tmax did not change appreciably [OR $0.21,95 \% \mathrm{CI}(0.05,0.84) ; \mathrm{p}=0.027$ ]. No patient demographic or clinical characteristic examined was significantly associated with Cmax and AUC in either univariable or multivariable analyses (data not shown). In the 333 patients who were on full dose peginterferon during the first 28 days, there were statistically significant unadjusted associations between a higher 28-day peginterferon level and both AA race [regression coefficient $\mathrm{b}=2.66,95 \% \mathrm{CI}=(0.89,4.43), \mathrm{p}=0.003]$ and lower BMI $[\mathrm{b}=-0.38,95 \% \mathrm{CI}=$ $(-0.52,-0.24), p<0.0001]$. When adjusted for age and gender, these associations remained significant [AA race: regression coefficient $\mathrm{b}=3.49,95 \% \mathrm{CI}=(1.76,5.20), \mathrm{p}=0.029$; BMI: regression coefficient $\mathrm{b}=-0.44,95 \% \mathrm{CI}=(-0.57,-0.30), \mathrm{p}=0.003]$.

\section{2,5-OAS Concentrations during Treatment}

Median and IQR serum 2,5-OAS concentrations in AA and CA patients from baseline through day 84 (week 12) of peginterferon and ribavirin treatment are shown in Figure 2A (day $0-7$ shown in insert). The baseline (day 0) serum 2,5-OAS concentration was significantly higher among AA than CA patients (139.5 vs. $106 \mathrm{pmol} / \mathrm{dL} ; \mathrm{p}<0.0001)$. Both AA and CA exhibited a rapid increase in 2,5-OAS concentrations following the first dose of peginterferon with maximum levels between days 3 and 7, and little change in concentrations thereafter. Serum 2,5-OAS concentrations were significantly higher in AA than in CA patients from day 1-56 of 
treatment (Fig. 2A). However, the fold-change in serum 2,5-OAS concentrations (relative to day 0) during the first 84 days ( $12 \mathrm{wk}$.) of therapy were similar in AA and CA patients, except for day 1 (1.53 vs. 1.67: $\mathrm{p}=0.02)$ and day 84 (1.92 vs. $2.31: \mathrm{p}=0.03$ ) when the increase was higher among CA (Fig. 2B).

\section{HCV RNA Concentrations during Treatment}

Median serum HCV RNA concentrations in AA and CA patients during the first 84 days (12 weeks) of treatment are shown in Figure 3. AA and CA had similar baseline serum HCV RNA levels, but different HCV RNA kinetics. AA had a triphasic HCV RNA pattern. The median HCV RNA level in AA patients decreased $0.9 \log _{10}$ from day $0-3$, followed in tandem by a $0.3 \log _{10}$ increase (rebound) between day 3 and 7 and a gradual $\left(3.0 \log _{10}\right)$ decline in HCV with a nadir at day 84. In contrast to AA, CA patients had a biphasic decline in HCV RNA between day 0 and 84 with a median $1.0 \log _{10}$ decline from day 0-3 followed by a more rapid (2.7 $\log _{10}$ ) drop in HCV RNA to a nadir at day 56. Compared to CA patients, AA patients had significantly higher serum HCV RNA concentrations from day 3 through day 56 . Consistent with the racial difference in viral kinetics, AA had lower rates of undetected serum HCV RNA at weeks 4 (10\% vs. $24 \%), 8$ (23\% vs. $46 \%)$ and 12 (44\% vs. 69$)$ than CA.

\section{Relationships between Peginterferon Pharmacokinetics, Pharmacodynamics (2,5-OAS) and Virologic Response}

The association between serum peginterferon, 2,5-OAS, and HCV RNA concentrations during the first 4 weeks of treatment was assessed using the Spearman correlation coefficient (r). There were significant negative correlations $(\mathrm{r} \geq 10.301)$ between serum peginterferon concentrations and serum HCV RNA on days $1(\mathrm{r}=-0.52), 2(\mathrm{r}=-0.48), 3(\mathrm{r}=-0.38), 7(\mathrm{r}=-0.34)$, and $14(\mathrm{r}$ $=-0.36)(\mathrm{p}<0.0001$ for each) among CA patients, but only on days $1(\mathrm{r}=-0.37)$ and $2(\mathrm{r}=$ $0.35)(\mathrm{p}<0.0001$ for each) among AA patients. With the exception of serum peginterferon on day 3 and 2,5-OAS on day 7 in $\mathrm{CA}(\mathrm{r}=0.30 ; \mathrm{p}=0.006)$, there were no significant correlations between serum peginterferon and serum 2,5-OAS concentrations in either racial group. Also, when adjusted for race, 2,5-OAS levels were not significantly associated with serum peginterferon levels over time in a linear mixed model. Linear mixed model analysis was also conducted to further determine the association between serum HCV RNA during the first 28 days and peginterferon PK parameters in 91 patients. Covariates included in the model were race, Cmax, Cmin, Tmax, serum peginterferon concentration, serum 2,5-OAS concentration and their interactions with time. CA race, higher peginterferon Cmax and AUC, shorter Tmax, and higher serum 2,5-OAS levels after the first dose were associated with lower serum HCV RNA levels at each time point (data not shown). Lower HCV RNA levels over the first 28 days were also significantly associated with CA race, higher serum peginterferon, and higher serum 2,5-OAS concentrations among the 333 patients. However, when both 2,5-OAS concentrations and peginterferon levels were used in the regression model, only peginterferon levels were significantly associated with HCV RNA levels.

The serial serum peginterferon concentrations and serum 2,5-OAS fold-changes in AA and CA patients stratified by EVR are shown in Figures 4 and 5, respectively. Compared to the nonresponders (NEVR), AA and CA patients with an EVR had greater serum peginterferon concentrations (Fig. 4A and Fig. 4B) and fold changes in 2,5-OAS (Fig. 5A and Fig. 5B) Compared to NEVR patients, peginterferon concentrations were significantly higher on days 1, 2, 7, and 28 in AA with EVR and on days 7, 56 and 84 in CA. In contrast, 2,5-OAS concentrations were significantly higher in AA with EVR on day 1, and on days 1,2, 7, and 14 in CA. Cmax, Cmin, AUC, and Tmax were not associated with EVR. Consistent with these results, both peginterferon levels on days 1, 2, 7, 28, 56, and 84 (Table 3) and the fold-changes in serum 2,5-OAS concentrations on days 1, 3, 7, and 14 (Table 4) (adjusted for race) were significantly associated with the probability of an EVR in a Poisson regression model that 
included an interaction between each variable and race. For each $1000 \mathrm{ng} / \mathrm{ml}$ increase in serum peginterferon concentration at each time point, EVR increased by $1-2 \%$. For every fold-change increase in serum 2,5-OAS level, EVR increased by 1-7\% with the strongest effects on days 1-14. Analyzed separately by race, the relationships between EVR and both serum peginterferon concentrations and serum 2,5-OAS fold-change in these models were more significant for AA than CA patients (data not shown). However, these racial differences might be related to the smaller number of patients without EVR among CA $(29 ; 17 \%)$ relative to AA $(56 ; 35 \%)$ patients.

\section{Discussion}

This study produced three major findings. First, serum peginterferon alfa-2a pharmacokinetics and pharmacodynamics (based on changes in serum 2,5-OAS levels) were similar in AA and CA patients infected with HCV genotype 1. Minor differences during the first few days of therapy were found, but ultimately similar levels of both markers were achieved. Second, patients who had a favorable virologic response to combination therapy (an EVR by week 12) had higher median serum peginterferon levels and fold-changes in serum 2,5-OAS levels than nonresponders. Third, AA patients had a lower virologic response rate than CA patients, despite similar peginterferon alfa-2a pharmacokinetic and pharmacodynamic responses. These results indicate that disparities in viral responses between AA and CA during peginterferon combination therapy cannot be explained by racial differences in peginterferon pharmacokinetics.

Pegylation decreases interferon clearance and increases its terminal half-life allowing the drugs to be administered once per week with superior efficacy compared to standard alpha interferon monotherapy. Pharmacokinetic studies have shown considerable inter-individual variability in serum peginterferon maximum concentrations and AUC achieved both following the first dose and during prolonged treatment. However, the significance of peginterferon pharmacokinetic variability to the outcomes of treatment remains uncertain. A population pharmacokinetic study among 900 patients with HCV infection selected from phase III multicenter peginterferon alfa- $2 \mathrm{~b}(0.5,1.0$, and $1.5 \mathrm{mcg} / \mathrm{kg} / \mathrm{wk})$ clinical trials found a significant association between the peginterferon concentration at week 4 and virologic responses at both week 4 and week 24 during therapy ${ }^{14}$. Another study compared serum peginterferon alfa-2a and 2,5-OAS levels in $15 \mathrm{HCV}$ patients who experienced less than a $1-\log _{10}$ reduction in serum HCV RNA (null responders) and 15 who had $\mathrm{a} \geq 2-\log _{10}$ decline in serum HCV RNA (complete responders) between baseline and day 28 of therapy ${ }^{9}$. Complete responders tended to have higher serum peginterferon and 2,5-OAS concentrations than null responders, but the differences were not significant. In addition, there was no significant correlation between serum peginterferon and serum 2,5-OAS concentrations. In a third study that compared peginterferon alfa- $2 \mathrm{a}$ and alfa- $2 \mathrm{~b}$ in 36 patients, the two pegylated formulations were found to have somewhat different pharmacokinetic and pharmacodynamic properties ${ }^{15}$. Nevertheless, patients in this study who had a $\geq 2-\log _{10}$ decline in serum HCV RNA during the first 8 weeks had significantly higher induction of 5 interferon-stimulated genes (2,5-OAS, IP10, ISG15, PKR, and ISG54) than patients with less than a $2-\log _{10}$ decline 15 . The inconsistencies between these studies might be explained by differences in sample sizes and statistical power.

Patient race, gender, baseline HCV RNA serum concentrations, Ishak fibrosis scores, the percentage of the maximum peginterferon dose taken during the first 24 weeks of treatment were independent predictors of SVR in HCV genotype 1 patients in the Virahep-C study ${ }^{4}$. Analysis of clinical factors did not reveal a basis for the racial difference in SVR rates.

Subsequent studies from the Virahep-C study have focused on other factors that might account for differences in antiviral response rates. The current analysis focused on whether differences in the outcome of treatment were related to differences in peginterferon pharmacokinetics and 
pharmacodynamics. To avoid the confounding effects of dose modifications by study investigators and patient noncompliance, only patients who were completely adherent to fulldose peginterferon during the first 4 weeks of combination therapy based on electronic drug monitoring were studied. Greater than $90 \%$ of AA and CA who met these criteria subsequently took $90 \%$ or more of the intended dose of peginterferon during the first 12 weeks treatment. In addition, this subset of patients had significantly higher EVR, end-of-treatment, and SVR than patients excluded from this analysis due to $<100 \%$ peginterferon adherence or peginterferon dose reductions. This probably explains why the EVR rate was slightly higher in this substudy (AA-65\%; CA-83\%) than reported in the total intention-to treat cohort (AA-61\%; CA-78\% ${ }^{4}$.

In keeping with prior pharmacokinetic studies, there was considerable inter-subject variability in peginterferon concentrations in both AA and CA patients. AA patients had a significantly shorter time to maximum serum peginterferon concentrations (Tmax), but in other regards, peginterferon pharmacokinetics (Cmax, AUC, and Cmin) following the first dose were similar in the two racial groups. In addition, AA patients had higher median peginterferon trough concentrations than CA patients during the first 28 days indicating a tendency to greater peginterferon exposure. Yet, both race groups achieved similar steady state peginterferon concentrations between weeks 8 and 12 . AA race was the only patient variable significantly associated with a shorter Tmax, whereas both AA race and a lower BMI were associated with higher day-28 peginterferon levels. Remarkably, AA patients in the current study achieved similar to higher peginterferon concentrations during the first 4 weeks than CA patients despite having greater median body weight and BMI. The basis for these racial differences in Tmax and peginterferon accumulation was not apparent.

For this study, changes in serum levels of 2,5-OAS was used as an indicator of peginterferon pharmacodynamic activity. Strikingly, AA patients had a higher median baseline serum 2,5OAS concentrations than CA patients, implying that AA may have a more robust activation of interferon induced genes in response to chronic HCV infection. The racial differences in baseline 2,5-OAS expression were not related to baseline HCV RNA levels which were similar in the two groups. High baseline levels of interferon-regulated genes may also be predictive of a poor response to interferon therapy. In a study published by Chen et al., pre-treatment levels of more than 10 interferon-stimulated gene RNA transcripts in liver biopsy tissue from patients with hepatitis $\mathrm{C}$ were found to be higher among those who subsequently failed to respond to antiviral therapy than those who responded ${ }^{16}$. Based on this association, it has been speculated that the higher endogenous production of type 1 interferon might saturate the response and prevent optimal stimulation of antiviral genes during the pharmacological administration of interferon. In the present study, however, there were no significant differences in baseline serum 2,5-OAS concentrations based on EVR in either AA or CA patients (data not shown). On the other hand, induction of most interferon-stimulated genes in peripheral blood mononuclear cells taken from patients before and during the first 28 days of combination therapy was blunted in patients with a poor antiviral response in other analyses from the Virahep-C trial ${ }^{17}$. Both AA and CA poor responders to combination therapy $(<1.5$ $\log _{10}$ reduction in HCV RNA levels by day 28) achieved lower levels of interferon stimulated genes than marked responders ( $>3.5 \log _{10}$ IU reduction in HCV RNA levels by day 28$) 17$. Similar findings have been reported by others. ${ }^{17}, 18$. These findings did not explain the racial differences in response rate to antiviral therapy. However, the smaller decrease in HCV RNA levels and the defective activation of interferon stimulated genes merely appeared to be more frequent in AA than CA patients.

Another important finding in this study was the strong association between higher serum levels of peginterferon and 2,5-OAS induction and a greater decline in serum HCV RNA during the first 4 weeks of treatment as well as the EVR. Consistent with previous reports, a higher BMI 
was strongly associated with lower peginterferon levels in the present study 14,19 . Peginterferon alfa plasma clearance is increased in obese patients relative to lean patients 14 , 19 . In addition, higher body weight has been associated with a lower SVR rate in some peginterferon and ribavirin clinical trials 20,21 . These results suggest that virologic response rates in overweight patients might be enhanced by a higher peginterferon dose than currently recommended. The role of higher peginterferon alfa-2a dosing in relation to body weight and non-response to conventional doses deserves further study. However, factors that control peginterferon accumulation are likely to be more complex than dose and body weight, since AA patients in the current study achieved similar to higher peginterferon concentrations during the first 4 weeks than CA patients despite having a greater median body weight and BMI.

In conclusion, peginterferon pharmacokinetic and pharmacodynamic variability based on serum 2,5-OAS are associated with EVR during peginterferon alfa-2a and ribavirin treatment in both AA and CA patients with HCV genotype 1 infection. This variability, however, does not explain the racial disparity in treatment efficacy. The basis for racial differences in virologic response is being addressed in ongoing ancillary genetics, immunology, virology, and interferon signaling studies in the Virahep-C cohort.

\section{Acknowledgments}

Financial Support: This Virahep-C study was a cooperative agreement funded by the NIDDK with a Cooperative Research and Development Agreement (CRADA) with Roche Laboratories, Inc. Grant numbers: U01 DK60329, U01 DK60340, U01 DK60324, U01 DK60344, U01 DK60327, U01 DK60335, U01 DK60352, U01 DK60342, U01 DK60345, U01 DK60309, U01 DK60346, U01 DK60349, U01 DK60341. Other support: National Center for Research Resources (NCRR) General Clinical Research Centers Program grants: M01 RR00645 (New York Presbyterian), M02 RR000079 (University of California, San Francisco), M01 RR16500 (University of Maryland), M01 RR000042 (University of Michigan), M01 RR00046 (University of North Carolina). Also supported by 1 K24 DK072036-01 (CDH).

\section{References}

1. Alter MJ, Kruszon-Moran D, Nainan OV, McQuillan GM, Gao F, Moyer LA, Kaslow RA, Margolis HS. The prevalence of hepatitis C infection in the United States, 1988 through 1999. N Engl J Med 1999;341:556-62. [PubMed: 10451460]

2. Muir AJ, Bornstein JD, Killenberg PG. Peginterferon alfa-2b and ribavirin for the treatment of chronic hepatitis C in blacks and non-hispanic whites. N Engl J Med 2004;350:2265-71. [PubMed: 15163776]

3. Jeffers L, Cassidy W, Howell CD, Hu S, Reddy KR. Peginterferon alfa-2a (40 kd) and ribavirin for black American patients with chronic hepatitis C virus genotype 1. Hepatology 2004;39:1702-08. [PubMed: 15185312]

4. Conjeevaram HS, Fried MW, Jeffers LJ, Terrault N, Wiley-Lucas T, Afdhal N, Brown RSJ, Belle SH, Robuck PR, Howell CD. Peginterferon and Ribavirin Treatment in African American and Caucasian American Patients with Chronic Hepatitis C Genotype 1. Gastroenterology 2006;31:470-7. [PubMed: 16890601]

5. Stark GR, Kerr IM, Williams BRG, Silverman RH, Schreiber RD. How cells respond to interferons. Annu Rev Biochem 1998;67:227-64. [PubMed: 9759489]

6. Ji X, Cheung R, Cooper S, Li Q, G H, He X. Interferon alfa regulated gene expression in patients initiating interferon treatment for chronic hepatitis C. Hepatology 2003;37:610-621. [PubMed: 12601359]

7. Glue P, Rouzier-Panis R, Raffanel C, Sabo R, Gupta S, Salfi M, Jacobs S, Clement RP. A dose-ranging study of pegylated interferon alfa-2b and ribavirin in chronic hepatitis C. Hepatol 2000;32:647-53.

8. Sulkowski M, Wright T, Rossi S, Arora S, Lamb M, Wang K, Gries JM, Yalamanchili S. Peginterferon alfa-2a does not alter the pharmacokinetics of methadone in patients with chronic hepatitis $\mathrm{C}$ undergoing methadone maintenance therapy. Clin Pharmacol Ther 2005;77:214-24. [PubMed: 15735615] 
9. Di Bisceglie AM, Fan X, Chambers T, Strinko J. Pharmacokinetics, pharmacodynamics, and hepatitis C viral kinetics during antiviral therapy: the null responder. J Med Virol 2006;78:446-51. [PubMed: 16566033]

10. Sowinski KM, Burlew BS, Johnson JA. Racial differences in sensitivity to the negative chronotropic effects of propranolol in healthy men. Clin Pharmacol Ther 1995;57:678-83. [PubMed: 7781268]

11. Sowinski KM, Lima JJ, Burlew BS, Massie JD, Johnson JA. Racial differences in propranolol enantiomer kinetics following simultaneous i.v. and oral administration. Br J Clin Pharmacol 1996;42:339-46. [PubMed: 8877025]

12. Hershman D, Weinberg M, Rosner Z, Alexis K, Tiersten A, Grann VR, Troxel A, Neugut AI. Ethnic neutropenia and treatment delay in African American women undergoing chemotherapy for earlystage breast cancer. J Natl Cancer Inst 2003;95:1545-8. [PubMed: 14559877]

13. Ribaudo HJ, Haas DW, Tierney C, Kim RB, Wilkinson GR, Gulick RM, Clifford DB, Marzolini C, Fletcher CV, Tashima KT, Kuritzkes DR, Acosta EP. Pharmacogenetics of plasma efavirenz exposure after treatment discontinuation: an Adult AIDS Clinical Trials Group Study. Clin Infect Dis 2006;42:401-7. [PubMed: 16392089]

14. Jen JF, Glue P, Ezzet F, Chung C, Gupta SK, Jacobs S, Hajian G. Population pharmacokinetic analysis of pegylated interferon alfa- $2 b$ and interferon alfa- $2 b$ in patients with chronic hepatitis $C$. Clin Pharmacol Ther 2001;69:407-21. [PubMed: 11406738]

15. Silva M, Poo J, Wagner F, Jackson M, Cutler D, Grace M, Bordens R, Cullen C, Harvey J, Laughlin M. A randomised trial to compare the pharmacokinetic, pharmacodynamic, and antiviral effects of peginterferon alfa- $2 \mathrm{~b}$ and peginterferon alfa-2a in patients with chronic hepatitis $\mathrm{C}$ (COMPARE). J Hepatol 2006;45:204-13. [PubMed: 16780997]

16. Chen L, Borozan I, Feld J, Sun J, Tannis LL, Coltescu C, Heathcote J, Edwards AM, McGilvray ID. Hepatic gene expression discriminates responders and nonresponders in treatment of chronic hepatitis C viral infection. Gastroenterology 2005;128:437-1444.

17. Taylor MW, Tsukahara T, Brodsky L, Schaley J, Sanda C, Stephens MJ, McClintick JN, Edenberg HJ, Li L, Tavis JE, Howell C, Belle SH. Changes in gene expression during pegylated interferon and ribavirin therapy of chronic hepatitis $\mathrm{C}$ virus distinguish responders from nonresponders to antiviral therapy. J Virol 2007;81:3391-401. [PubMed: 17267482]

18. He XS, Ji X, Hale MB, Cheung R, Ahmed A, Guo Y, Nolan GP, Pfeffer LM, Wright TL, Risch N, Tibshirani R, Greenberg HB. Global transcriptional response to interferon is a determinant of HCV treatment outcome and is modified by race. Hepatology 2006;44:352-9. [PubMed: 16871572]

19. Lam NP, Pitrak D, Speralakis R, Lau AH, Wiley TE, Layden TJ. Effect of obesity on pharmacokinetics and biologic effect of interferon-alpha in hepatitis C. Dig Dis Sci 1997;42:178-85. [PubMed: 9009135]

20. Manns MP, McHutchison JG, Gordon SC, Rustgi VK, Shiffman M, Reindollar R, Goodman ZD, Koury K, Ling MH, Albrecht JK. Peginterferon alfa-2b plus ribavirin compared with interferon alfa-2b plus ribavirin for initial treatment of chronic hepatitis $\mathrm{C}$ : a randomised trial. The Lancet 2001;358:958-965.

21. Fried MW, Shiffman ML, Reddy KR, Smith C, Marinos G, Goncales FL, Haussinger D, Diago M, Carosi G, Dhumeaux D, Craxi A, Lin A, Hoffman J, Yu J. Peginterferon alfa-2a plus ribavirin for chronic hepatitis C. N Engl J Med 2002;347:975-982. [PubMed: 12324553]

\section{Abbreviations}

AA

African American(s)

CA

Caucasian American(s)

HCV

hepatitis $\mathrm{C}$ virus

\section{OAS}

Clin Gastroenterol Hepatol. Author manuscript; available in PMC 2009 July 1. 
oligoadenylate synthetase

EVR

early virologic response

Virahep-C

study of viral resistance to antiviral therapy for chronic hepatitis C

Cmax

maximum serum concentration

Cmin

minimum or trough serum concentration

Tmax

time to maximum serum concentration

AUC

area under the serum concentration-time curve

BMI

body mass index 


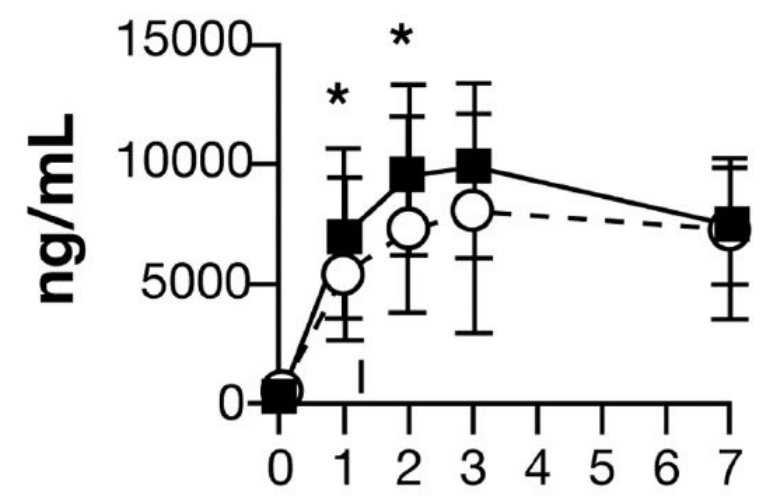

Day

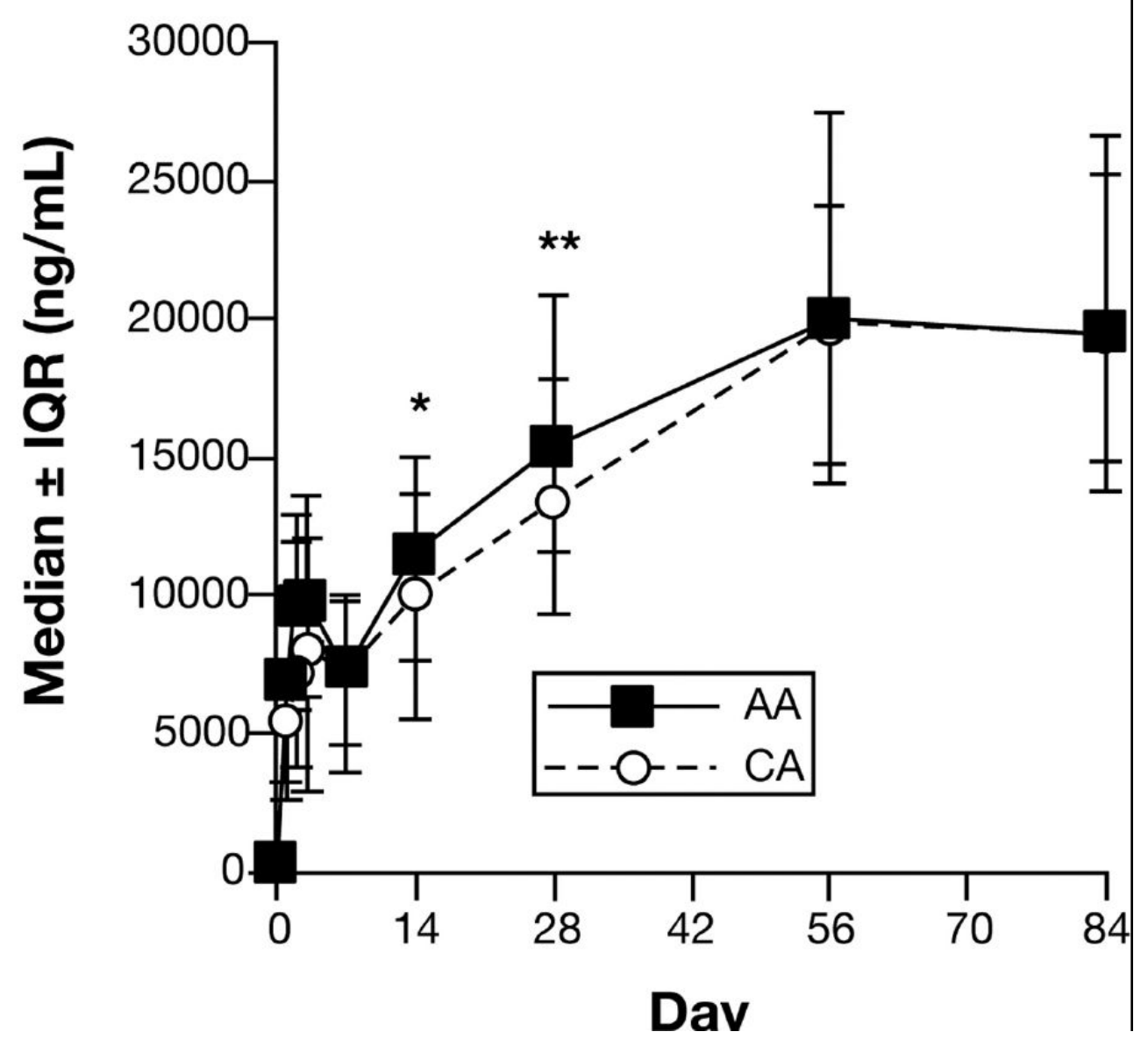

Figure 1. Serum Peginterferon alfa-2a concentrations

Serum peginterferon concentrations were measured by enzyme-linked immunoassay in patients infected with HCV genotype 1 as described in Materials and Methods. Results expressed as median \pm interquartile range (IQR). The numbers of observations at each time point ranged between 141 and 153 for AA and 157 and 168 for CA, except for day 3 (AA = 40; $\mathrm{CA}=51$ ). Results were compared between AA and CA using the Wilcoxon rank-sum test. 
A
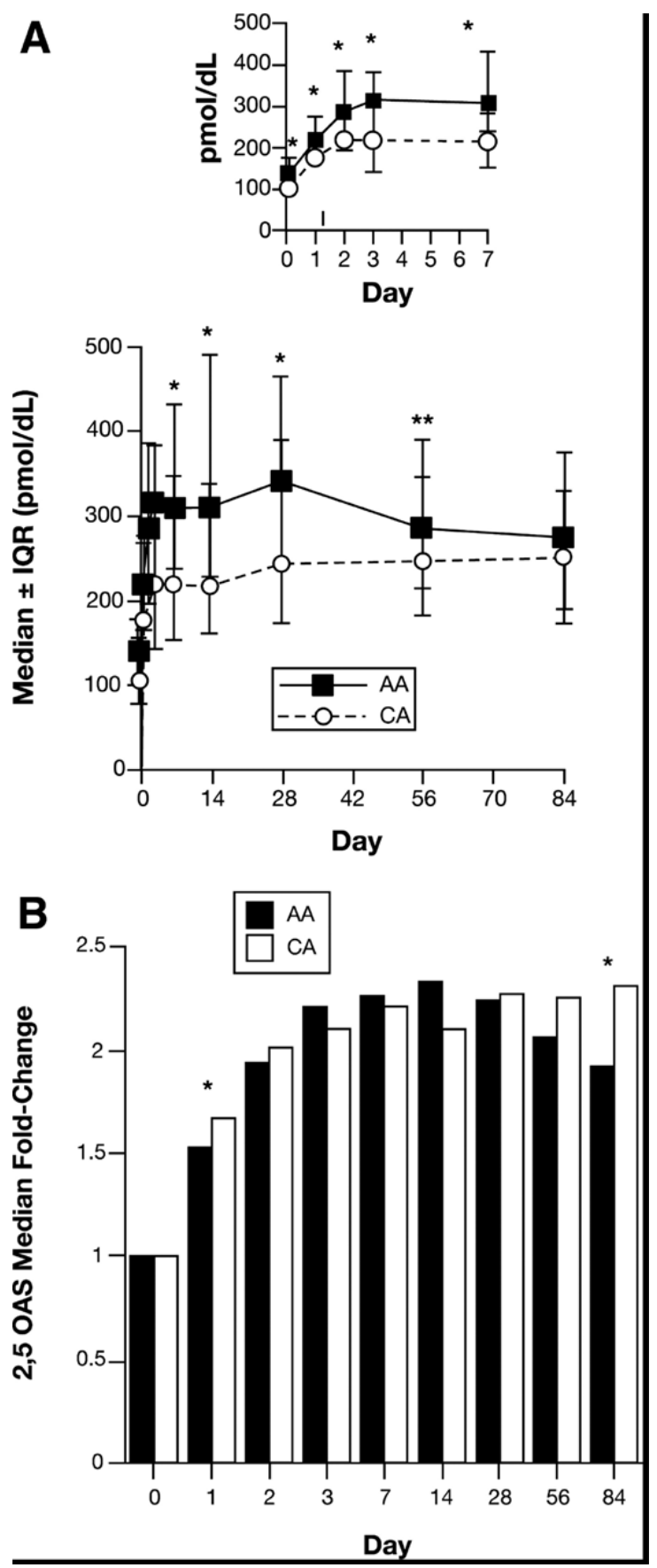

Figure 2. Serum 2,5-OAS Fold-change

Serum 2,5-OAS activity was determined in patients infected with HCV genotype 1 using a commercially available radioimmunoassay (RIA) kit as described in Materials and Methods. The numbers of observations at each time point ranged between 153 and 160 for AA and 159 and 167 for $\mathrm{CA}$, except for day $3(\mathrm{AA}=72 ; \mathrm{CA}=84)$. A) Results expressed as median \pm interquartile range (IQR). B) Data expressed as fold change at each day (2,5-OAS concentration $/ 2,5-\mathrm{OAS}$ concentration on day 0 ). Results were compared between AA ad CA using the Wilcoxon rank-sum test. 


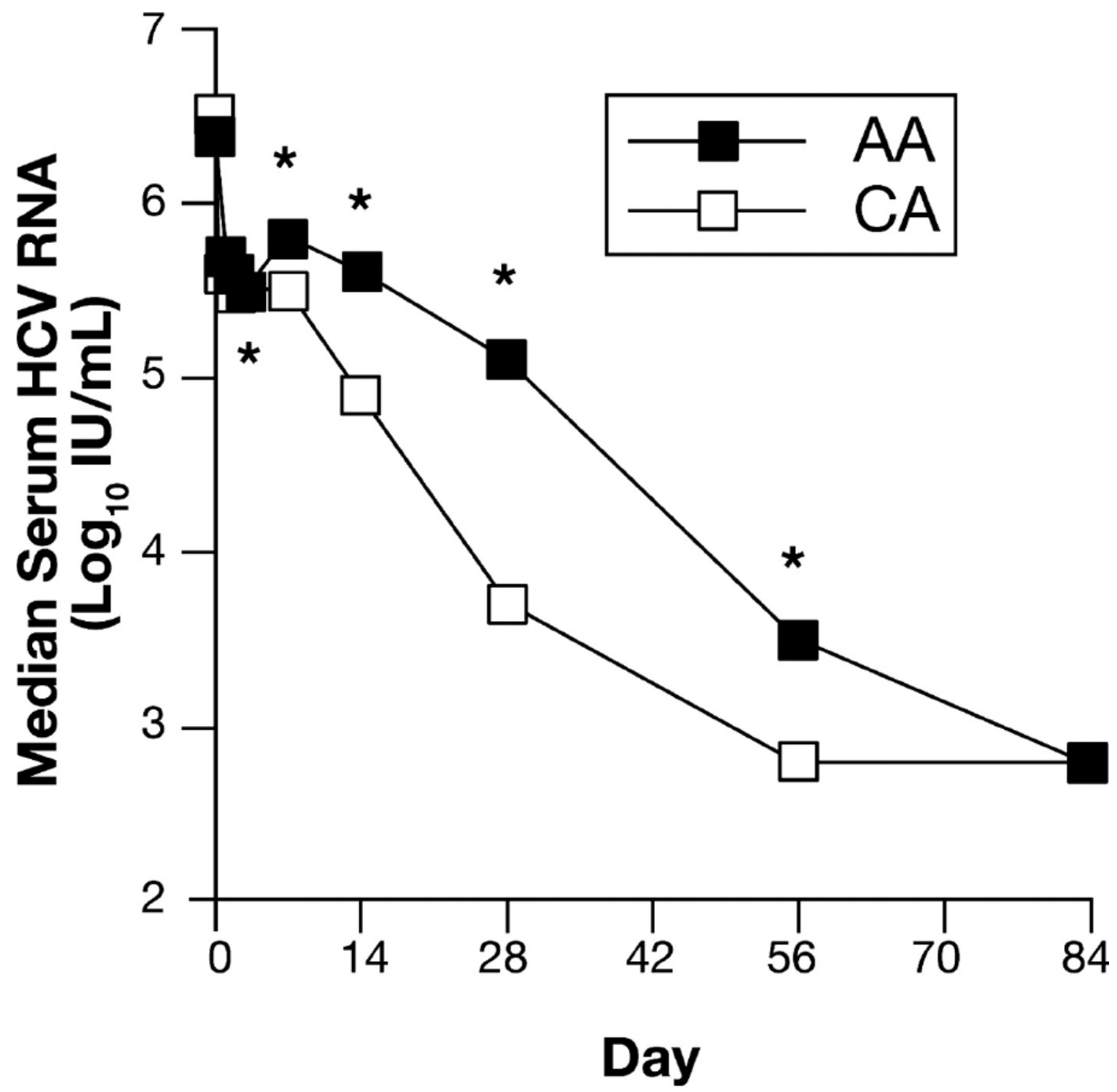

Figure 3. Serum HCV RNA Kinetics

Serum HCV RNA concentrations were measured in duplicate using the AmplicorTM assay (sensitivity $50 \mathrm{IU} / \mathrm{ml}$. Roche Molecular Diagnostics). The numbers of observations at each time point ranged between 149 and 160 for AA and 167 and 173 for CA, except for day 3 (AA $=72 ; \mathrm{CA}=85$ ). Results were compared between AA and CA using the Wilcoxon rank-sum test. 

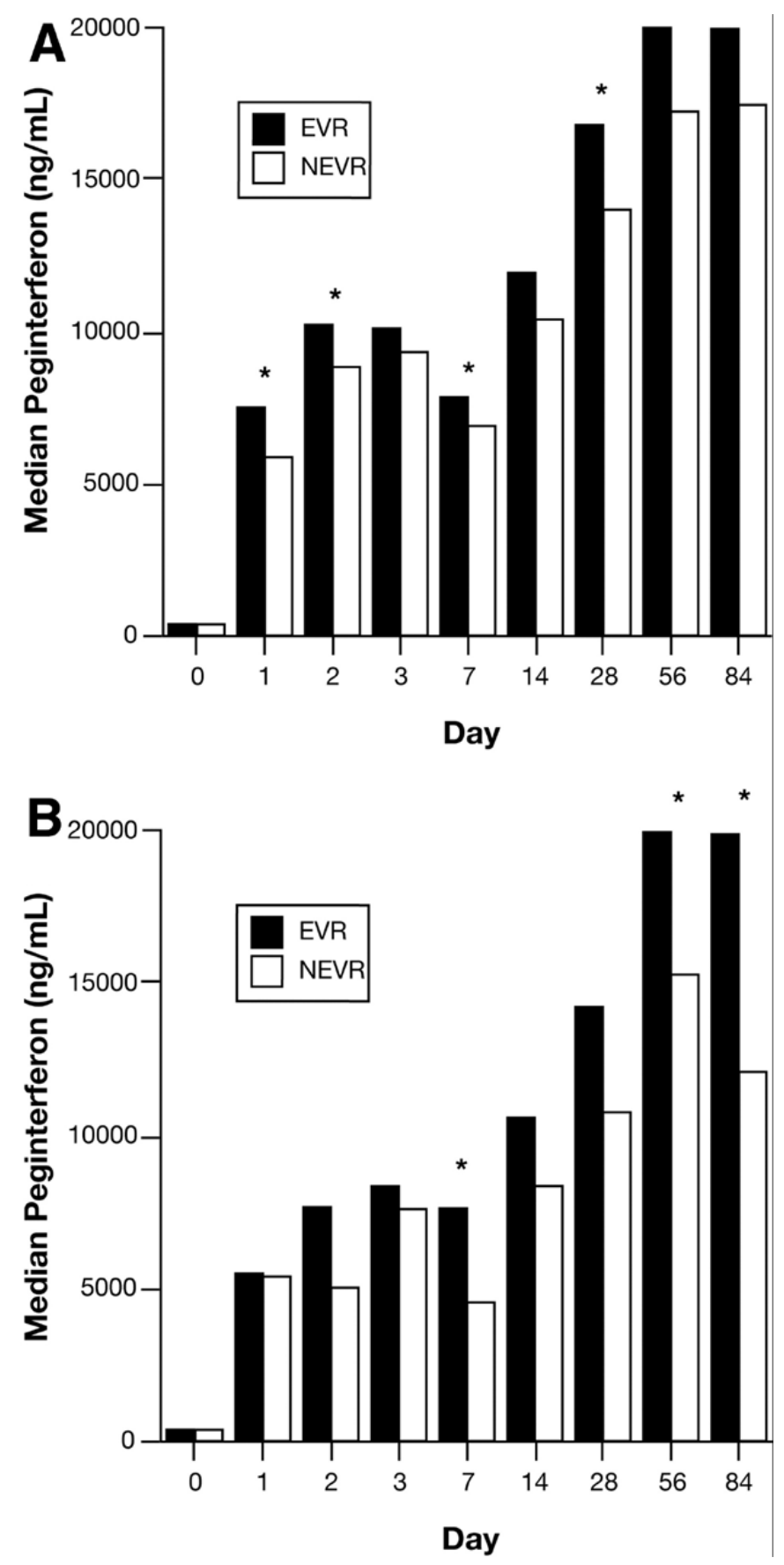

Figure 4. Serum peginterferon alfa-2a and EVR in AA (A) and CA (B) patients

Serum peginterferon concentrations were measured by ELISA as described in Materials and Methods. EVR was defined as a $>2-\log _{10}$ decline in serum HCV RNA or undetected serum HCV RNA at week-12 relative to week-0. Results were compared between EVR and NEVR using the Wilcoxon rank-sum test. 

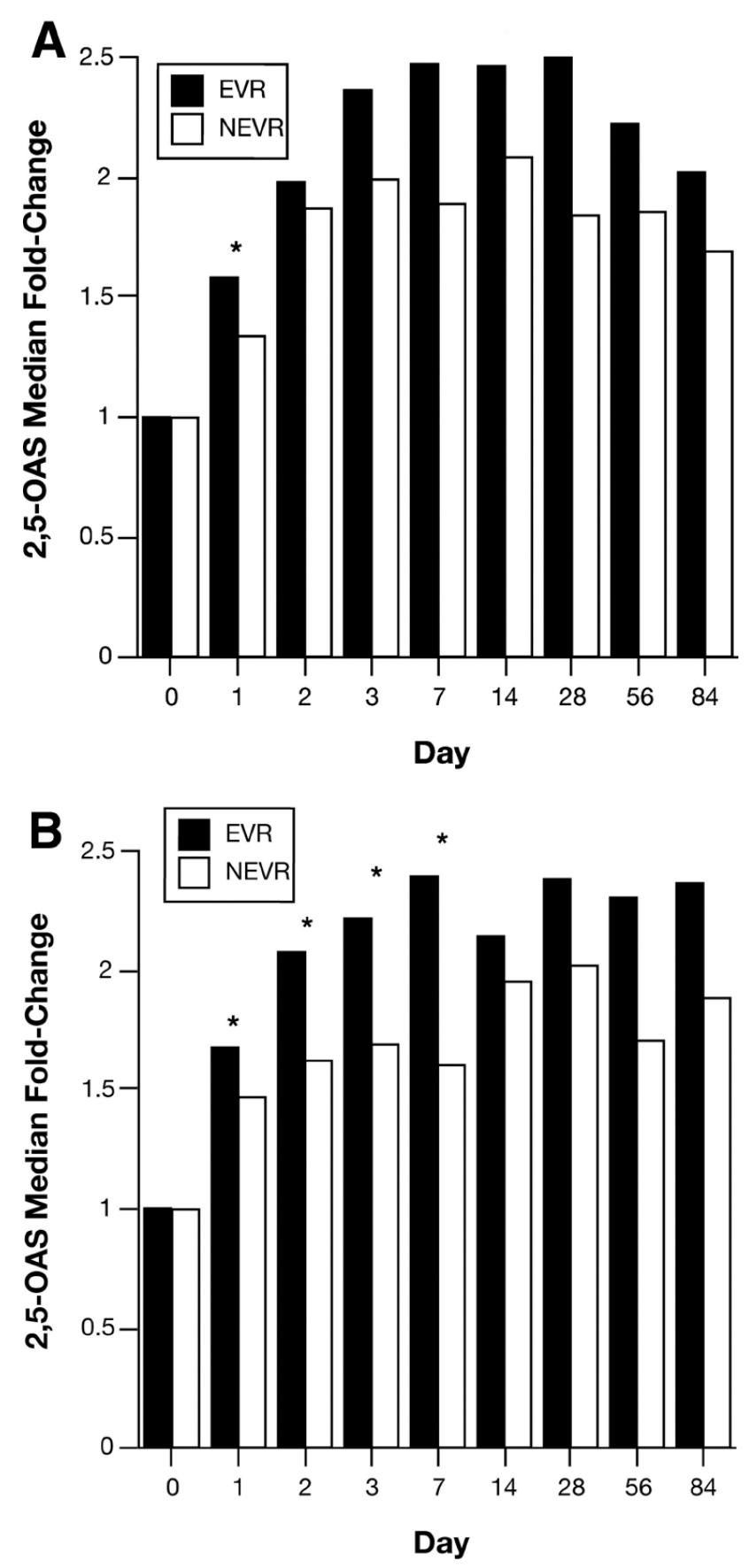

Figure 5. Serum 2,5-OAS fold-change and EVR in AA (A) and CA (B) patients

Serum 2,5-OAS concentrations were measured by RIA as described in Materials and Methods. Data expressed as fold change on each day relative to day 0 as described in figure 2 . The EVR was defined as in figure 4 and in Materials and Methods. Results were compared between EVR and NEVR using the Wilcoxon rank-sum. 
Baseline patient characteristics.

Table 1

\begin{tabular}{|c|c|c|c|}
\hline Characteristic & African Americans $(\mathrm{n}=160)$ & Caucasian Americans $(n=173)$ & p-value ${ }^{* * *}$ \\
\hline Male & $107(67 \%)$ & $119(69 \%)$ & 0.71 \\
\hline Age (years) ${ }^{*}$ & $49(45,53)$ & $48(43,52)$ & 0.08 \\
\hline Duration of Infection (years) $^{*}$ & $25(18,32)$ & $27.0(20,33)$ & 0.16 \\
\hline Weight $(\mathrm{kg})^{*}$ & $87.3(78.9,102.5)$ & $82.6(73.5,97.1)$ & 0.004 \\
\hline Body Mass Index $\left(\mathrm{kg} / \mathrm{m}^{2}\right)^{*}$ & $29.5(26.3,34.0)$ & $27.6(24.8,31.7)$ & 0.003 \\
\hline History of diabetes & $23(14 \%)$ & $5(3 \%)$ & 0.0002 \\
\hline History of hypertension & $69(43 \%)$ & $39(23 \%)$ & $<0.0001$ \\
\hline \multicolumn{4}{|l|}{ Current alcohol use (drinks/day) $\mathrm{p}=0.50$} \\
\hline$<1$ & $138(89 \%)$ & $147(87 \%)$ & 0.57 \\
\hline 1 to $<2$ & $8(5 \%)$ & $14(8 \%)$ & 0.26 \\
\hline$\geq 2$ & $9(6 \%)$ & $8(5 \%)$ & 0.67 \\
\hline Currently smoking & $66(42.3)$ & $58(33.9)$ & 0.12 \\
\hline ALT (IU/L) & $59.5(41,88)$ & $76(53,140)$ & $<0.0001$ \\
\hline Albumin $(\mathrm{g} / \mathrm{dL})^{*}$ & $4.1(3.8,4.3)$ & $4.2(4.0,4.4)$ & 0.0008 \\
\hline Total Bilirubin $(\mathrm{mg} / \mathrm{dL})^{*}$ & $0.6(0.4,0.8)$ & $0.7(0.5,0.9)$ & 0.006 \\
\hline Prothrombin time (INR) ${ }^{*}$ & $1.0(0.9,1.1)$ & $1.0(0.9,1.1)$ & 0.93 \\
\hline Ishak Necroinflammatory Score $(0-18)^{*}$ & $10(8,12)$ & $11(8,13)$ & 0.15 \\
\hline Ishak Fibrosis Score $(0-6)^{*}$ & $2(1,3)$ & $2(1,3)$ & 0.24 \\
\hline Bridging fibrosis and cirrhosis & $54(34 \%)$ & $69(40 \%)$ & 0.28 \\
\hline Steatosis ( $\geq 5 \%$ present) $[\mathrm{n}(\%)]$ & $46(29 \%)$ & $64(37 \%)$ & 0.13 \\
\hline \multicolumn{4}{|l|}{ HCV subtype $[\mathrm{n}(\%)] \mathrm{p}=0.002$} \\
\hline $1 \mathrm{a}$ & $77(48 \%)$ & $93(54 \%)$ & 0.30 \\
\hline $1 \mathrm{~b}$ & $74(46 \%)$ & $54(31 \%)$ & 0.005 \\
\hline HCV RNA level $\left(\times 10^{6} \mathrm{IU} / \mathrm{ml}\right){ }^{*}$ & $6.4(5.6,6.7)$ & $6.5(5.7,6.8)$ & 0.26 \\
\hline
\end{tabular}

* Continuous variables represented by median $\left(25^{\text {th }}\right.$ percentile, $75^{\text {th }}$ percentile)

** The Wilcoxon rank sum test was used to compare distributions for continuous variables. Pearson's chi-square test was used to compare percentages 
Table 2

Peginterferon alfa-2a noncompartmental pharmacokinetic parameters

\begin{tabular}{|c|c|c|c|}
\hline Parameter & AA $(n=40)$ & $\mathrm{CA}(\mathrm{n}=51)$ & p-value \\
\hline $\mathrm{Cmax}(\mathrm{ng} / \mathrm{mL})$ & $12.0(7.7,16.0)$ & $10.1(6.6,13.9)$ & 0.18 \\
\hline Cmin (ng/mL) & $6.8(3.5,8.9)$ & $7.6(4.6,9.9)$ & 0.55 \\
\hline \multicolumn{4}{|l|}{$\operatorname{Tmax}\left(\right.$ day) ${ }^{*}$} \\
\hline 1 & $2(5.0)$ & $7(13.7)$ & \multirow{4}{*}{0.045} \\
\hline 2 & $13(32.5)$ & $12(23.5)$ & \\
\hline 3 & $22(55.0)$ & $19(37.3)$ & \\
\hline 7 & $3(7.5)$ & $13(25.5)$ & \\
\hline $\operatorname{AUC}\left(\mathrm{ng}^{*} \mathrm{hr} / \mathrm{mL}\right)$ & $1413(969,1926)$ & $1201(759,1738)$ & 0.24 \\
\hline Accumulation ratio ${ }^{* *}$ & $3.3(2.6,4.9)$ & $2.9(2.2,4.2)$ & 0.23 \\
\hline
\end{tabular}

Values are expressed as median (IQR)

P-values correspond to two-sample Wilcoxon rank tests for Cmax, Cmin, AUC, and Accumulation ratio.

* Tmax values reported as n (\%), p-value derived from Pearson's chi-square test of association.

**

Ratio of the week 24 and week 1 peginterferon Cmin values 
Table 3

Relative risk of EVR as a function of serum peginterferon concentration (per $1000 \mathrm{ng} / \mathrm{ml}$ ) by treatment day adjusted for race.

\begin{tabular}{|c|c|r|}
\hline Treatment Day & Relative Risk (95\% CI) $^{\boldsymbol{a}}$ & p-value \\
\hline $\mathbf{1}$ & $1.02(1.0045,1.03)$ & 0.0073 \\
\hline $\mathbf{2}$ & $1.01(1.0055,1.02)$ & 0.0010 \\
\hline $\mathbf{3}$ & $1.01(0.99,1.02)$ & 0.4854 \\
\hline $\mathbf{7}$ & $1.02(1.0108,1.04)$ & 0.0003 \\
\hline $\mathbf{1 4}$ & $1.01(1.00,1.02)$ & 0.1541 \\
\hline $\mathbf{2 8}$ & $1.01(1.002,1.02)$ & 0.0159 \\
\hline $\mathbf{5 6}$ & $1.01(1.0085,1.02)$ & $<.0001$ \\
\hline $\mathbf{8 4}$ & $1.01(1.0035,1.02)$ & 0.0020 \\
\hline
\end{tabular}

${ }^{a}$ For every $1000 \mathrm{ng} / \mathrm{ml}$ increase in serum peginterferon concentration, EVR increased by $1-2 \%$ 
Table 4

Relative risk of EVR as a function of serum OAS fold-change by treatment day adjusted for race.

\begin{tabular}{|c|c|c|}
\hline Treatment Day & Relative Risk (95\% CI) & p-value \\
\hline $\mathbf{1}$ & $1.04(1.00,1.07)$ & 0.047 \\
\hline $\mathbf{2}$ & $1.04(0.99,1.09)$ & 0.12 \\
\hline $\mathbf{3}$ & $1.07(1.02,1.12)$ & 0.005 \\
\hline $\mathbf{7}$ & $1.06(1.02,1.09)$ & 0.001 \\
\hline $\mathbf{1 4}$ & $1.04(1.00,1.08)$ & 0.037 \\
\hline $\mathbf{2 8}$ & $1.02(0.98,1.06)$ & 0.33 \\
\hline $\mathbf{5 6}$ & $1.01(0.97,1.05)$ & 0.68 \\
\hline $\mathbf{8 4}$ & $1.02(0.996,1.04)$ & 0.11 \\
\hline
\end{tabular}

${ }^{a}$ For every fold-change increase in serum 2,5-OAS level, EVR increased by $1-7 \%$ 